\title{
Human Neural Stem Cell Therapy for Chronic Ischemic Stroke: Charting Progress from Laboratory to Patients
}

\author{
John D. Sinden, Caroline Hicks, Paul Stroemer, Indira Vishnubhatla, and Randolph Corteling
}

Chronic disability after stroke represents a major unmet neurologic need. ReNeuron's development of a human neural stem cell (hNSC) therapy for chronic disability after stroke is progressing through early clinical studies. A Phase I trial has recently been published, showing no safety concerns and some promising signs of efficacy. A single-arm Phase II multicenter trial in patients with stable upper-limb paresis has recently completed recruitment. The hNSCs administrated are from a manufactured, conditionally immortalized hNSC line (ReNeuron's CTX0E03 or CTX), generated with c-mycER ${ }^{\mathrm{TAM}}$ technology. This technology has enabled CTX to be manufactured at large scale under cGMP conditions, ensuring sufficient supply to meets the demands of research, clinical development, and, eventually, the market. CTX has key pro-angiogenic, pro-neurogenic, and immunomodulatory characteristics that are mechanistically important in functional recovery poststroke. This review covers the progress of CTX cell therapy from its laboratory origins to the clinic, concluding with a look into the late stage clinical future.

Keywords: stroke disability, neural stem cell therapy, preclinical studies, mechanisms of action, clinical trials

\section{Introduction}

\section{Stem cells and stroke}

$\mathrm{T}$ HE PAST DECADE HAS SEEN a rise in the number of stem cell-derived therapies targeting ischemic stroke in preclinical and early clinical studies. Corroborated by numerous scientific reports, the therapeutic benefits of stem cells include an extension of the time window for drug intervention, improvement of neurological deficits, reduction of infarct volume, pro-regenerative cerebral reorganization, mitigation of poststroke neuro-inflammation, and tissue restoration, all of which depend on the time after infarct, cell type used, and route of administration [1-3]. The wide range of effects observed for stem cell therapies demonstrates that functional recovery after stroke occurs via multiple mechanisms rather than a single target [4-6]. Research indicates that the mode of action may depend on the stem cell type and other key factors, including infarct size and location, mode of intervention, and timing poststroke [6-8]. Thus, some understanding of the cellular, molecular, and biochemical events that are involved in the mode of action of a stem cell type is a prerequisite to improving and optimizing its therapeutic benefits.

Our 2012 review of cell therapy in stroke showed the wide variety of cell types used preclinically and clinically in stroke treatment research [1]. Mesenchymal stromal cells
(MSCs) of multiple origins and phenotypes are most commonly employed in the literature and mainly applied systemically in high doses in acute stroke settings, because of their nonengraftment and potent "drug-like" biological activity. Neural stem cells (NSCs), by contrast, are multipotent cells that are derived from developing or adult brain tissue or differentiated from pluripotent cells such as embryonic stem cells (ESCs) or induced pluripotent stem cells (iPSCs) in culture. These stem cells have both capacity for engraftment and neural cell differentiation as well as potent biological activity and are delivered intracerebrally in smaller volumes and cell doses; we believe that they are more suitable in patients presenting with pre-existing chronic, stable disability. Currently, there is a growing number of hNSC-derived therapies in preclinical development for ischemic stroke (Table 1). Leading these therapies, ReNeuron's CTX0E03 cell line (CTX) has been evaluated in a first-in-human, single-center trial in patients with moderate-to-severe disability, 6 months to 5 years after ischemic stroke [9]. Currently, a Phase II stroke trial in patients with upper-limb disability, 3-12 months poststroke is underway across multiple sites in the United Kingdom (clinicaltrials.gov NCT02117635). In this review, we summarize nearly 15 years of research behind the CTX line and discuss its mode of action together with implications for therapeutic potential in stroke disability.

ReNeuron, Pencoed, Bridgend, United Kingdom.

(C) John D. Sinden et al. 2017; Published by Mary Ann Liebert, Inc. This is an Open Access article distributed under the terms of the Creative Commons Attribution License, which permits unrestricted use, distribution, and reproduction in any medium, provided the original work is properly cited. 


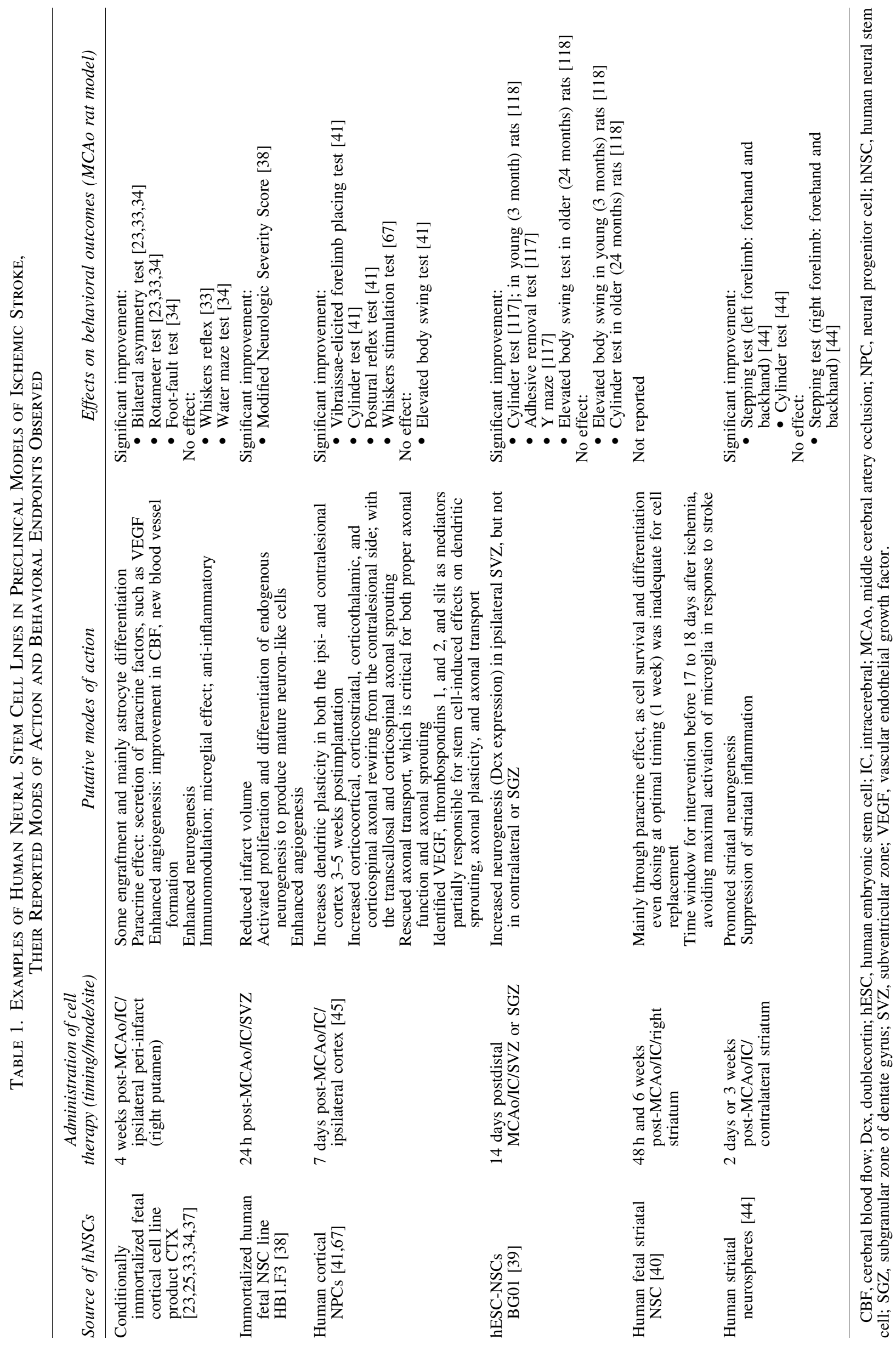




\section{Technical Development of hNSC Therapy Products for CNS Indications}

\section{Cell transplantation}

Progress in a cell therapy approach for CNS indications is dependent on product safety and efficacy and a manufacturing strategy to provide a product of consistent quality and supply to meet the demands of experimental and clinical research and the future commercial market. Early studies demonstrated that transplanted primary fetal neural cells can survive and exert positive effects in animal models of neurological indications, including ischemic stroke damage [10-12]. Preclinical and clinical studies established anecdotal proof-of-concept data for their therapeutic efficacy and tested the surgical feasibility of safe CNS implantation. However, the use of primary cells from donated fetal brain tissue is impractical as a widely available therapeutic strategy. Procurement of tissues is limited by supply and the quality (ie, purity and homogeneity of cells) is variable, producing inconsistent clinical results [13].

\section{Use of NSCs}

The use of human neural stem or neural progenitor cell lines is a practical alternative to primary cell implants for brain repair. Stem cells can be expanded in culture, with the potential to deliver treatment at scale. Human neural stem cells (hNSCs) can be expanded in defined media supported by growth factors, such as epidermal growth factor (EGF) and fibroblast growth factor (FGF-2), and cultured as monolayers or free-floating neurospheres [14]. At the time of CTX's derivation, hNSCs were most efficiently isolated from fetal brain tissue. However, equivalent cell types can now be obtained from ESC and iPSC origins.

Some limitations for using hNSCs have surfaced, including their limited expandability in culture and issues related to genetic/phenotypic instability [15-17]. Neurospheres, for example, may contain mixed populations of stem cells and progenitors at differing stages of development, which may prevent the expansion of a homogenous cell line and limit their clinical potential [18]. In contrast, genetically immortalized NSCs, using genes for transcription factors such as Myc, have proved to be highly effective in extending the life span of hNSCs in vitro and in maintaining a stable genotype and phenotype $[19,20]$. Long-term cell expansion with associated karyotype stability is a feature of Myc immortalization [17,21]. Moreover, current reports indicate that the myc gene may be a "stemness" gene that drives rapid proliferation while maintaining the multipotent capability of stem cells [22].

\section{c-mycE ${ }^{T A M}$ conditional immortalization technology}

ReNeuron generated CTX, a genetically stable, conditionally immortalized, clonal hNSC line, by using its proprietary c-mycER ${ }^{\mathrm{TAM}}$ stem cell expansion technology (Fig. 1) $[10,18,23]$. CTX is genetically modified by the insertion of a single copy of the c-myc gene fused with a modified murine

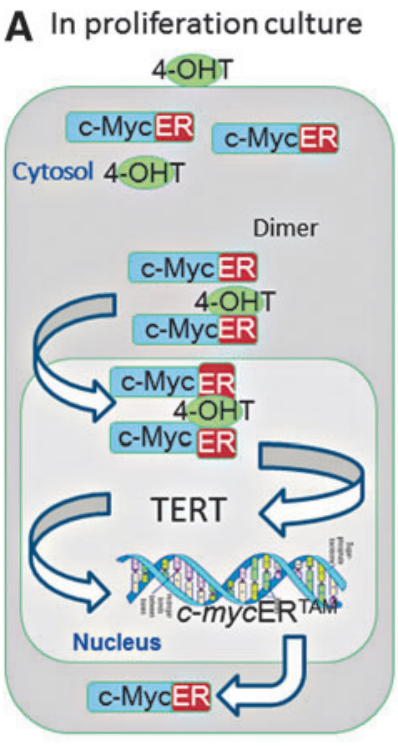

Proliferation/ Self-renewal
B Removal of 4-OHT

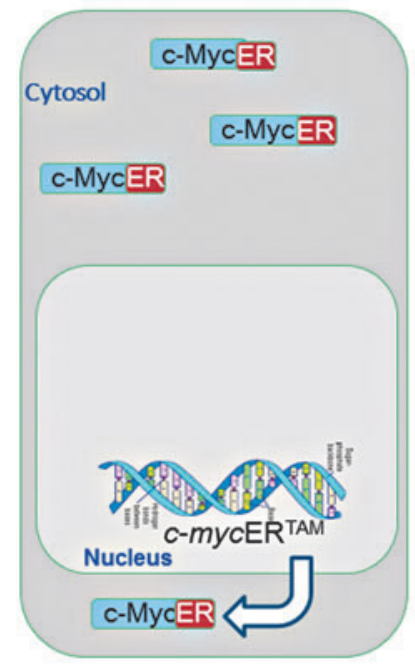

Differentiation
C In vivo environment

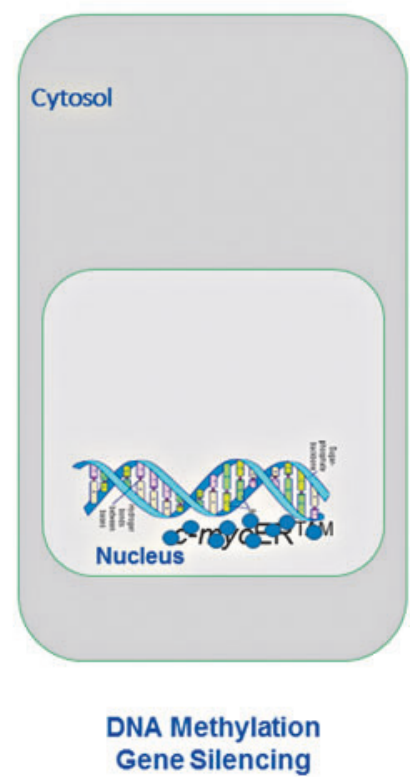

FIG. 1. Conditional growth of CTXOE03 is dependent on the presence of 4-hydroxytamoxifen. (A) Proliferation: The conditional immortalizing gene c-mycER ${ }^{\mathrm{TAM}}$ generates a fusion protein of c-Myc and a hormone receptor [estrogen receptor (ER)] that is regulated by 4-hydroxytamoxifen (4-OHT). In the presence of 4-OHT, the fusion protein (c-MycER) forms a dimer that translocates into the cell nucleus. Once in the nucleus, the dimer c-MycER activates the cell cycle and regulates the transcription of telomerase reverse transcriptase (TERT), which controls long-term cell division with genetic stability. (B) Removal of 4-OHT: When 4-OHT is removed from the cell media, the fusion proteins no longer form dimers and remain in the cytoplasm. Cell division is markedly reduced. Cells then begin to differentiate into neural phenotypes. (C) In vivo environment: When cells are implanted into the brain, the c-mycER ${ }^{\mathrm{TAM}}$ gene is effectively "silenced" within 7 days by methylation of the promoter sequence. Thus, the fusion protein is no longer expressed. 
Table 2. Identity, Stability, and Potency Tests That Are Employed to Characterize CTX Cell Banks and/or Drug Products (for Phase II Trial)

\begin{tabular}{|c|c|}
\hline Test & Outcome \\
\hline PCR Sequencing of cDNA & $\begin{array}{l}\text { Sequence of insert conforms to transgene identity. No insertions, } \\
\text { deletions, or mutations from expected sequence }\end{array}$ \\
\hline $\begin{array}{l}\text { Determination of Flanking Nucleotide } \\
\text { Sequence }\end{array}$ & Consistent with published sequence \\
\hline PCR across integration site & PCR across integration site confirms cell line identity \\
\hline Karyology & Comparable with published normal chromosome, male XY \\
\hline Viability and growth & $\begin{array}{l}\geq 70 \% \text { viability on recovery. Viable cell numbers at least double } \\
\text { within } 7 \text { days }\end{array}$ \\
\hline c-mycER ${ }^{\text {TAM }}$ gene copy number (PCR) & Modal $\sim 1($ range $0.87-3.46)$ \\
\hline Phenotypic marker (Nestin) & At least $95 \%$ of cells are Nestin positive \\
\hline $\begin{array}{l}\text { Position, sequence, and indication of number } \\
\text { of integrated target gene by fluorescent } \\
\text { in situ hybridization }\end{array}$ & $\begin{array}{l}\text { Chromosomal (Chr 13) localization of integrated c-mycER } \\
\text { sequences }\end{array}$ \\
\hline Potency & $\begin{array}{l}\text { Cell dose-dependent IL-10 production in co-culture with U937 monocyte } \\
\text { cell line }\end{array}$ \\
\hline Neural differentiation & $\begin{array}{l}\text { Upregulation of Tub- } \beta 3 \text {, GFAP, and GAL-C marker expression } \\
\text { by qPCR after seeding into Alvatex }{ }^{\circledR} \text { three-dimensional cell matrix }\end{array}$ \\
\hline
\end{tabular}

IL, interleukin; PCR, polymerase chain reaction; qPCR, quantitative PCR.

estrogen receptor (ER) $[18,23,24]$. The transgene expresses a recombinant protein $\left(\mathrm{c}-\mathrm{MycER}^{\mathrm{TAM}}\right)$, which is present as an inactive monomer in the cytosol of the cell [24]. The activity of the recombinant fusion protein is controlled exclusively by the addition of the 4-hydroxytamoxifen (4-OHT) to the cell culture media; 4-OHT binds to the modified receptor and causes the protein to dimerize. The protein dimer translocates to the nucleus, where c-Myc acts as a transcription factor to maintain cell division in the presence of growth factors in the media. The cMyc protein enables cell cloning and increased cell proliferation as well as extends the stable growth of cells by the upregulation of telomerase activity and other c-Myc targets. In the absence of 4-OHT and the mitogenic growth factors in the media, both in vitro and after cell implantation, the $\mathrm{c}-\mathrm{MycER}^{\mathrm{TAM}}$ fusion protein remains in the cytoplasm and is inactivated. Under these conditions, the cells undergo growth arrest and can differentiate into neurons and glial cells both in vitro and in vivo [23]. The CTX cell line in culture remains dependent on mitogenic growth factors for significant proliferative capacity and the presence of 4-OHT to enhance cell growth to permit exponential proliferation. Telomerase activity, which supports karyotype stability across repeated cell doublings, is also 4-OHT dose dependent [23]. In CTX in vitro, the c-MycER protein is gradually downregulated on growth arrest and neural differentiation. The c-mycER gene is epigenetically silenced by methylation of the CPG islands of the promoter element of the construct, at least 1 week after cell implantation in stroke rats [25].

\section{CTX cell line generation, banking, and manufacturing of drug products}

The CTX cell line was originally selected after both in vitro and in vivo screening of several cell lines based on its stable NSC phenotype, survival, and differentiation into relevant cell lineages in vivo $[10,18,23]$. The CTX cell line is clonal, expands rapidly in culture, and has a normal karyotype [23]. The approach we have followed is to progress cell expansion/ manufacturing through a cell banking process, in line with procedures that have been used to manufacture biologicals such as recombinant proteins or antibodies [10]. This approach can allow a sustainable supply of standardized material for preclinical safety studies and potentially all the way to marketing authorization. To achieve this goal, CTX cell lines were generated to make "master" and "working" cell banks of frozen vials of cells from which reproducible clinical lots of drug substance and drug product batches can be derived, as required. The resultant CTX "Drug Product" (CTX-DP) is composed of CTX cells at a passage of $\leq 37$ [23]. Clinical release criteria include measures of sterility, purity (cell number, cell viability), and a number of other tests of identity, stability, and potency that are required for clinical product release or for information, as requested by regulatory authorities (Table 2). The active DP is a fresh or frozen suspension of living cells formulated in a proprietary excipient (Hypothermosol FRS; Biolife Solutions, Bothell, WA) that is suitable for intracranial administration by using stereotaxic surgical techniques. CTXDP may be stored at $4^{\circ} \mathrm{C}$ to $25^{\circ} \mathrm{C}$ for extended periods (hours to days). Currently, the CTX clinical DP is an "off the shelf" cryopreserved product in a solvent-free excipient (US Patent 9265795) with a shelf life of many months.

Initiation of the strategy of cell banking of the CTX cell line early in its developmental program has ensured that all pivotal preclinical safety and efficacy studies were conducted by using the DP material equivalent to that used in ongoing or subsequent clinical trials. Importantly, CTX will not need to be re-derived, as sufficient vials are available at every level of the manufacturing process to enable potentially limitless manufacture. Robotic automation of the CTX manufacturing process has also been demonstrated [26], further validating the potential of this cell line to be efficiently and safely scaled at a reasonable cost of goods.

\section{Preclinical Studies of hNSCs in Chronic Ischemic Stroke}

For clinical translation of any cell therapy product, regulatory authorities require evidence of therapeutic efficacy in animal models, together with extensive data to support product quality (cell characteristics and quality assurance regarding cells, their manipulation and manufacturing), and in vivo 
safety in acute and long-term toxicology and tumorigenicity studies. Critical issues related to cellular therapeutic strategy, impacting patient selection (such as age, anatomic location, and size of infarct), functional targets, timing of transplantation, dose of cells, site and route for delivery, and requirement for immunosuppression, should be assessed in preclinical models, wherever possible, prior to clinical translation. The most widely used, characterized, and validated animal model of ischemic stroke is the middle cerebral artery occlusion (MCAo) in the rat $[27,28]$. The MCAo lesion in this model demonstrates the same ischemic territory (ie, basal ganglia and sensorimotor cortex) as the human brain after ischemic stroke. This animal model exhibits the same core functional deficits such as unilateral paresis, sensory dysfunction, and visuospatial neglect. However, it does not reproduce the heterogeneity of human stroke. The MCAo model permits investigation of the key aspects of stroke pathophysiology to examine potential therapeutic agents with a minimal sample size. Its use and reproducibility across laboratories has accrued sufficient evidence of potential efficacy to justify clinical development.

\section{Toxicology and in vivo safety}

Standard toxicology designs, using functional observational batteries, hematology, and necropsy endpoints, can be used to assess acute and long-term product safety. Evaluation of exogenous cell survival, proliferation, migration, and differentiation of implanted cells is necessary for both tumorigenicity and biodistribution assessments. Full in vivo biodistribution analysis requires the use of validated stem cell-specific markers and methods, such as immunohistochemistry, in situ hybridization, or quantitative PCR (qPCR), to detect implanted cells. These studies require pilot feasibility and validation studies and suitable controls to eliminate false positives. For tumorigenicity studies, these methods are implemented to confirm the cellular origin of any forming tumors.

Stem cell-derived therapy products that are implanted, including hNSCs, require extensive safety testing. CTX safety has been evaluated across a battery of preclinical studies. After intracerebral implantation of CTX in MCAo rats, nonhuman primates, and NOD SCID mice, general safety was assessed by a functional observation battery of tests for a maximum of 12 months. No CTX-related adverse events were reported in any of these studies. Both the cell dose and volume of implant were well tolerated in all studies conducted (ReNeuron Internal Report; [29]).

In terms of tumorigenicity, cell therapy products need thorough evaluation. Long-term safety evaluation requires investigation of tumorigenic potential in large cohorts of animals by using the clinical route of administration. For these studies, it is usual to implant cells into immunodeficient strains of mice by using large numbers to give the best chance of cell survival and to maximize the chance of tumor formation. The duration of studies will vary depending on the survival time of the cells, which can range from about 3 months for nonengrafting cell types to 12 months or longer for cells that survive well in vivo. For CTX, long-term survival required for in-life tumorigenicity studies was only achievable in the MCAo model. In this system, CTX cells at 12 months postimplantation were not proliferative and showed no evidence of tumor formation. In addition, longterm (9 months) treatment of CTX-implanted MCAo animals with tamoxifen had no impact on CTX cell survival and proliferation, with no CTX-related reports of tumor formation (ReNeuron Internal Report; [29]).

Neoplasm formation has never been observed with CTX cells across multiple preclinical studies. This information is, nonetheless, important in assessing the inherent risk of using a genetically modified cell line for clinical applications. In addition, because of the presence of the c-myc gene and its single-site retroviral insertion, further CTX implantation studies were undertaken to demonstrate c-mycER gene transcript and protein downregulation and epigenetic silencing in vivo, as described earlier [25].

Studies in vitro have also confirmed that re-exposure of growth arrested/differentiated cells to 4-OHT does not return differentiated CTX cells to a proliferative state (ReNeuron Internal Report; [29]). Further, CTX cells do not proliferate when exposed to endogenous steroid hormones, showing that activation of the c-myc $\mathrm{ER}^{\mathrm{TAM}}$ technology is specific for the 4OHT ligand. Together, these data support the view that CTX is safe and does not present a tumor risk after implantation into the brain.

\section{In vivo efficacy}

A validated MCAo rat model of ischemic stroke was used for nonclinical CTX efficacy studies [30-32]. This model is well characterized in terms of sensorimotor and cognitive dysfunctions that are associated with region-specific stroke damage [28]. For CTX, evaluation rats were transplanted 34 weeks postocclusion, permitting prior recovery from acute phase neurological dysfunction and establishment of steadystate sensorimotor deficits.

Three MCAo studies have demonstrated long-term improvements in sensorimotor function after intracerebral CTX implantation. In the first study, animals were treated with methylprednisolone for 2 weeks after cell administration and with cyclosporine A for the remaining duration of the study. Transplantation of CTX cells into the striatum in this study caused statistically significant improvements in both sensorimotor function and gross motor asymmetry at 6-12 weeks postimplantation [23]. In the second study, CTX delivered adjacent to the infarcted region demonstrated a cell dose-response effect [33]. Again, animals were treated with methylprednisolone and cyclosporine A; however, for this study, treatment was only given for the first 2 weeks after cell administration. Recovery in sensorimotor function deficits (bilateral asymmetry test in the mid- and high-dose groups and the rotameter test after amphetamine exposure in the high-dose group) was found in the CTX-implanted groups compared with the vehicle group [33]. In-life functional improvements correlated with cell dose; however, there were no statistically significant correlations between surviving CTX cell numbers and test performances.

In the third study, intraparenchymal (but not intraventricular) implantation of CTX cells in the rat MCAo model improved sensorimotor dysfunction (bilateral asymmetry test) and motor deficits (foot-fault test, rotameter) [34]. Importantly, analyses based on lesion topology (striatal versus striatal plus cortical damage) revealed a significantly greater $(\sim 80 \%)$ functional improvement in animals with a stroke confined to the striatum [34]. Cell survival 3 months postimplant was positively correlated with infarct size, but there was no correlation between cell survival and motor improvement. 
Key factors affecting neurological recovery and therapeutic efficacy

The brain environment alters dramatically and dynamically after the initial insult of stroke and presents in varying anatomical regions at any given time point. Therefore, the timing and mode of administration are of clinical relevance in terms of different types of cell therapies and mode of action. In the clinical scenario, early systemic delivery of cell therapy (within $36 \mathrm{~h}$ after the stroke event) is aimed as a neuroprotective strategy to reduce the cascade of injury and to limit brain tissue loss. But, the restoration of cerebral blood flow (CBF) beyond a critical time cannot rescue irreversibly damaged brain cells, which leads to long-term disability observed in stroke survivors. In this setting, cell therapy administered weeks, months, and years poststroke targets the functional recovery of stable or deteriorating neural systems. This chronic stage is of interest to the majority of hNSC therapies that are currently in development (Table 1). During this period, the therapeutic opportunity is "brain repair," including neurogenesis, angiogenesis, growth factor secretion, engraftment, and cell differentiation [33,35-40].

The majority of hNSC experimental stroke studies have used stereotaxic intracerebral delivery to place the cells in close proximity to the lesion and to increase their survival (Table 1) $[23,25,33,34,36-39,41-45]$. Hicks et al. [37] determined time-related CTX cell survival in the striatum of naive mice after implantation and found that the substantial and rapid reduction of the implanted CTX cells by day 7 was due to apoptosis. In the MCAo model, CTX cells implanted 4 weeks postlesion were observed in $37 \%$ (10/27) of the treated cohort at 12 weeks postimplantation by using immunofluorescence methods. Cell survival was not influenced by dose concentration $\left(22 \%(2 / 9)\right.$ of low-dose $\left(4.5 \times 10^{2}\right.$ cells $)$, $56 \%(5 / 9)$ of medium-dose $\left(4.5 \times 10^{3}\right.$ cells $)$, and $33 \%(3 / 9)$ of high-dose animals $\left(4.5 \times 10^{5}\right.$ cells $)$ in this study) [33]. In another MCAo study, the quantification of CTX survival at 1 and 4 weeks postimplantation by Alu qPCR showed the presence of CTX cells in all grafted brains, which ranged between $6.3 \%$ and $39.8 \%$ of the total cells administered [25]. These findings are consistent with other reports of the loss or short-term survival of implanted hNSCs $[40,42,46]$. Further, a time course study following the fate of CTX cells postimplantation into both the ipsilateral and contralateral striatum of MCAo rats demonstrated a significant loss of implanted cells between 2 and 7 days postimplantation. At time points beyond 7 days and for a maximum of 6 months after implantation, CTX cells demonstrated better survival in the lesioned compared with the nonlesioned hemisphere [ReNeuron internal report].

\section{Implantation site and lesion topology}

The extent to which the site of implantation and host environment influence the fate of hNSCs after intracerebral transplantation also needs consideration. Appropriate placement of cells is an important factor that is of clinical relevance and that affects therapeutic outcome. The poststroke brain manifests specific microenvironments that can influence implantation efficacy. Two contrasting sites-intracerebroventricular (ICV) and the peri-infarct environments-were compared for implantation efficacy [34]. The ICV environment is similar to the lesion environment as it contains cerebrospinal fluid throughout. However, it lacks both microvascular blood supply and an extracellular matrix to support the integration and survival of implanted cells: An ICV injection of CTX cells did not result in any improvement. In contrast, the peri-infarct environment provides an extracellular matrix together with ischemia-induced changes, such as increased vasculature, neuronal loss, and gliosis. When implanted into peri-infarct tissue, CTX cells survived and gradual improvements in sensorimotor dysfunctions (bilateral asymmetry test) and motor deficits (foot-fault test and rotameter) were noted between 4 and 12 weeks postimplantation [34].

Lesion topology indicated that rats with stroke damage confined to the striatum recovered dysfunction to control levels after striatal CTX cell implantation. Animals with striatal lesions showed a more substantial improvement (83\%) with CTX cell implantation, compared with animals with striatal and cortical lesions (48\% improvement) [34].

\section{Mechanisms of Action of hNSCs in Ischemic Stroke}

\section{Cellular infarct reconstruction}

An understanding of the cellular, molecular, and biochemical events involved in mechanisms of action of cell therapy is essential to improve and optimize its therapeutic benefit. Two main NSC-based strategies for the mechanism of action have been explored in animal models. The first strategy is via the replacement of neurons to potentially reconstruct and repair the stroke-damaged neural circuitry by using intracerebral implanted NSCs or stimulation of neurogenesis through endogenous NSCs $[47,48]$. In the second strategy, NSCs on delivery to the brain [intracerebral, intravenous (IV), or intra-arterial (IA)] act via paracrine mechanisms to promote immunomodulatory and neuroprotective mechanisms, endogenous neurogenesis, and angiogenesis [37,49]. A recent proposal of a "biobridge" by the Borlongan laboratory, using a Notchmodified MSC line, links both strategies and suggests that the therapeutic benefit is derived via a combination of direct cell transplantation and changes to the microenvironment via paracrine actions of administered cells [50]. In models of traumatic brain injury, the administered cells aid in the creation of the biobridge by using MMP-dense signals. Importantly, on completion of the biobridge, the administered cells defer the repair process to endogenous neurogenic cells [51]. As the newly generated host cells replace the implanted cells, the implanted cells die, leaving only endogenous cells to maintain the bridge between the subventricular zone (SVZ) and the injured site [50]. The role of the biobridge in stroke models using intracerebrally implanted hNSCs warrants further investigation.

\section{Possibility for direct cell replacement as a mechanism of repair}

Direct cell replacement as a mechanism for repair poststroke has been, to a degree, discounted as therapeutic benefits cannot be attributed solely to implanted cell survival and/or differentiation [37,52]. As presented in the Key Factors Affecting Neurological Recovery and Therapeutic Efficacy section earlier, studies using CTX have consistently reported variable incidence of cell survival (1\% to $58 \%$ ) after implantation. This variability may be accounted for by 
sampling limitations, the method used to detect and quantify the cells, and the site and timing of administration postocclusion. The peri-infarct environment has been shown to favor implanted cell survival over nonischemic or infarct environments $[34,45,53]$.

Stroemer et al. [33] observed that the majority of the surviving CTX cells were found either in or close to the intracranial injection site. Any migration of implanted cells was restricted to the lesioned striatum ipsilateral to implantation [33]. Studies using other hNSCs have also consistently reported cell migration to ischemic regions, after administration via various routes such as intracranial implantation [42], IV [54], or IA [55]. Intracerebrally implanted hNSCs were reported to have migrated up to $1.2 \mathrm{~mm}$ in the lesioned hemispheres compared with $0.2 \mathrm{~mm}$ in the naive rat brain [45]. In another study, delaying implantation ( $48 \mathrm{~h}$ to 6 weeks after ischemic insult) did not affect the magnitude of migration, neuronal differentiation, and proliferation of the implanted hNSCs [42]. Further, surviving hNSCs displayed a wide spectrum of fates, ranging from $78 \%$ remaining in an immature state [41] weeks after implantation, to unquantified numbers of differentiated neurons forming synapses with host cells [56].

Characterization of CTX phenotype postintracerebral implantation showed expression of vascular-specific markers, CD31, CD62, and Flt4, and the oligodendroglial marker, Olig2 in a small proportion of surviving CTX cells in the MCAo brain [33]. Smith et al. [34], however, reported that 3 months after implantation into stroke brains, almost $20 \%$ of CTX cells were glial fibrillary acidic protein positive $\left(\mathrm{GFAP}^{+}\right)$astrocytes, and less than $2 \%$ expressed the neuronal marker, FOX3.

In summary, studies of implanted CTX have shown variable and limited long-term survival rates in MCAo rats; of these, only a small percentage of implanted cells expressed neural markers $[33,36]$. These results do not support the hypothesis that stem cell therapeutic effects can be solely attributed to neuronal replacement and are consistent with data from other studies [4-6,38].

\section{Host tissue responses}

After the implantation of CTX cells, there was a significant increase in cell proliferation in the host brains, which may have partly contributed to postocclusion repair and protection of the penumbra and led to enhanced compensatory networks arising elsewhere $[33,36]$. The reason that implanted hNSCs generally increase endogenous neurogenesis may be due to the production of certain growth factors or the repression of inflammation and apoptosis [57,58]. Human NSCs can express several neurotrophic factors, including EGF, FGFs, glial cell line-derived neurotrophic factor 1 alpha (GDNF), sonic hedgehog (Shh), stromal cell-derived factor 1 alpha (SDF1-alpha), and vascular endothelial growth factor (VEGF) [59-61]. Also, it has been shown that implanted hNSCs can repress the expression of caspase-3 and upregulate the activity of heat shock protein 27 (HSP27) to reduce apoptosis [58]. These paracrine activities of NSCs provide a microenvironment that is more favorable to host cells and, thus, leads to proliferation of endogenous NSCs and suppression of apoptosis.

\section{Immunomodulatory/anti-inflammatory effect}

The SVZ is an essential source of new cells in the developing brain, and remnants of these zones are known to persist into adulthood. In the adult rodent brain, the SVZ contains proliferating progenitor cells and relatively quiescent NSCs [62]. After MCAo, there is a significant decrease in the number of Ki67-positive cells in the SVZ, indicating a reduction in cell division and a likely reduction in neurogenesis and gliagenesis. Implantation of CTX into MCAolesion brains significantly restored host proliferation in the neurogenic SVZ [33]. These findings are in agreement with reports using other hNSCs [49,63]. Ekdahl et al. [63] also attributed the decreased neurogenesis to inflammation; however, increased proliferation in the SVZ has also been noted at relatively early time points after injury in the adult brain $[48,64,65]$. The study by Stroemer et al. [33] suggested that at 3 months poststroke, an inflammatory mechanism may operate to suppress cell proliferation and that an anti-inflammatory influence may be exerted by CTX at an early stage postimplantation to counteract the effects of MCAo. Although the phenotype of the newly born cells was not determined in that study; it is highly likely that these cells in the SVZ would have differentiated into neurons, astrocytes, and oligodendrocytes [66]. Horie et al. [67], using hNSCs from neurosphere cultures, showed fewer ionizing calcium-binding adaptor molecule 1 (Iba-1) positive monocytes/macrophages 1-2 weeks postimplantation. Interestingly, this immunomodulatory effect was blocked by the anti-VEGF antibody Avastin, indicating that VEGF was important in hNSC immunomodulation.

Human MSCs have been shown to have a profound inhibitory effect on T cell proliferation and cytotoxicity [68]. There is also evidence that hNSC modulation of macrophage/microglia and endothelial cells occurs in the ischemic lesion area [69]. The underlying mechanisms of the immunosuppressive effect of CTX and other hNSCs involve several soluble molecules such as nitric oxide, the enzyme indoleamine 2,3-dioxygenase (IDO), transforming growth factor- $\beta 1$ (TGF- $\beta 1$ ), hepatocyte growth factor, interleukin (IL)-10, IL-6, and soluble human leukocyte antigen (HLA)-G5, and they are only partly understood [70-72]. The enzyme IDO is also activated during inflammation and drives toward conditions that favor immune suppression and tolerance [73]. High levels of IDO protein in the brain have been linked to neurological disorders. Repression of IDO appears to improve these diseases. When CTX cells were treated with interferon- $\gamma$, they dramatically upregulated IDO mRNA and protein expression [74]. A group of naturally occurring flavonoid phytochemicals were found to potently repress the CTX-IDO activity, independently of gene expression and protein translation, suggesting a mechanism to attenuate the IDO activity without damaging the hNSCs.

In ischemic situations, there is a large increase in necrotic cells: Their lysis and resulting content release leads to inflammatory macrophage (M1) responses $\left(\mathrm{CD} 68^{+}, \mathrm{CD} 80^{+}\right.$, $\mathrm{CCR} 7^{+}$), which are pro-inflammatory/tissue destructive and counterproductive in an ischemic injury repair setting [75]. In contrast, in general tissue homeostasis, the removal of apoptotic cells enables tissue remodeling and repair. It is believed that the uptake of apoptotic cells leads to polarization of the macrophages toward the $\mathrm{M} 2, \mathrm{CD}^{+} 3^{+} / \mathrm{CD} 168^{+}$, anti-inflammatory, tissue constructive type, which secrete cytokines such as IL-10, IL-4, IL-13, and prostaglandin E2 in the local environment and promote wound repair [75,76].

Postimplantation, a substantial proportion of the CTX cells undergoes rapid apoptosis over a period of $24-72 \mathrm{~h}$, with an exponential decline in cell numbers. In vivo, apoptotic cells 
are removed rapidly (within minutes) by tissue macrophages and bystander cells. Engulfment of apoptotic cells by macrophages promotes $\mathrm{M} 2$ polarization, resulting in tissue repair and angiogenesis. Furthermore, anaerobic conditions lead to hypoxia-inducible factor-1 (HIF-1) activation in macrophages. This, in combination with an M2 macrophage phenotype, upregulates pro-vascularization factors (eg, phosphatidylinositolglycan biosynthesis class $\mathrm{F}$ protein, VEGF) and endothelial chemoattractants. In vitro studies indicate that the addition of viable CTX cells to U937 cells in culture promote them to an M2 phenotype, showing the expression of CD206 and IL-10 release (Fig. 2).

Therefore, it could be predicted that M2 polarization of macrophages, particularly in the presence of hypoxia in vivo, underlies an important component of the therapeutic benefit of injecting CTX cells directly into tissues.

\section{Microglia and stimulation of endogenous neurogenesis}

The hypothesis that hNSC-mediated recovery in ischemic stroke conditions involves the neuroprotective action of microglial populations and the recruitment of a proliferative neuroblast population has gathered considerable support $[36,43,77,78]$.

It has recently been shown in humans that neurogenesis arising from the SVZ is seen not only in the olfactory bulb but also, more prominently, in striatal regions [79]. Hassani et al. [36] reported evidence for a pool of endogenous proliferating cells in the rat striatum consisting of neuroblasts and microglial cells, which were generated in response to MCAo and implantation of CTX hNSCs. There was no effect of stroke on the ventral SVZ and although there was an effect of stroke on the presence of proliferating cells in the dorsal SVZ, there was no CTX effect in this region. There were changes to the proliferative population in the striatum in response to stroke, and these were enhanced by CTX implantation. CTX enhanced microglial responses at both 1 and 4 weeks post-CTX treatment in MCAo. In contrast, a significant increase in the presence of dividing neuroblasts was only afforded by CTX implantation in the MCAo brain at 4 weeks postimplantation. These data suggest that the primary effect of CTX may be by modulation of the microglia response. It is possible that paracrine factors secreted by the microglia promote recruitment of dividing neuroblasts or have a neuroprotective action to support and maintain the neuroblast population and contribute to the therapeutic effect of CTX.

\section{Evidence for angiogenesis, tubule formation, and neovascularization}

Angiogenesis contributes to the functional recovery of the ischemic region, with increased collateral circulation to repair damaged vasculature $[80,81]$. Implanted CTX cells were also found to increase CBF on the lesioned side in MCAo-lesioned
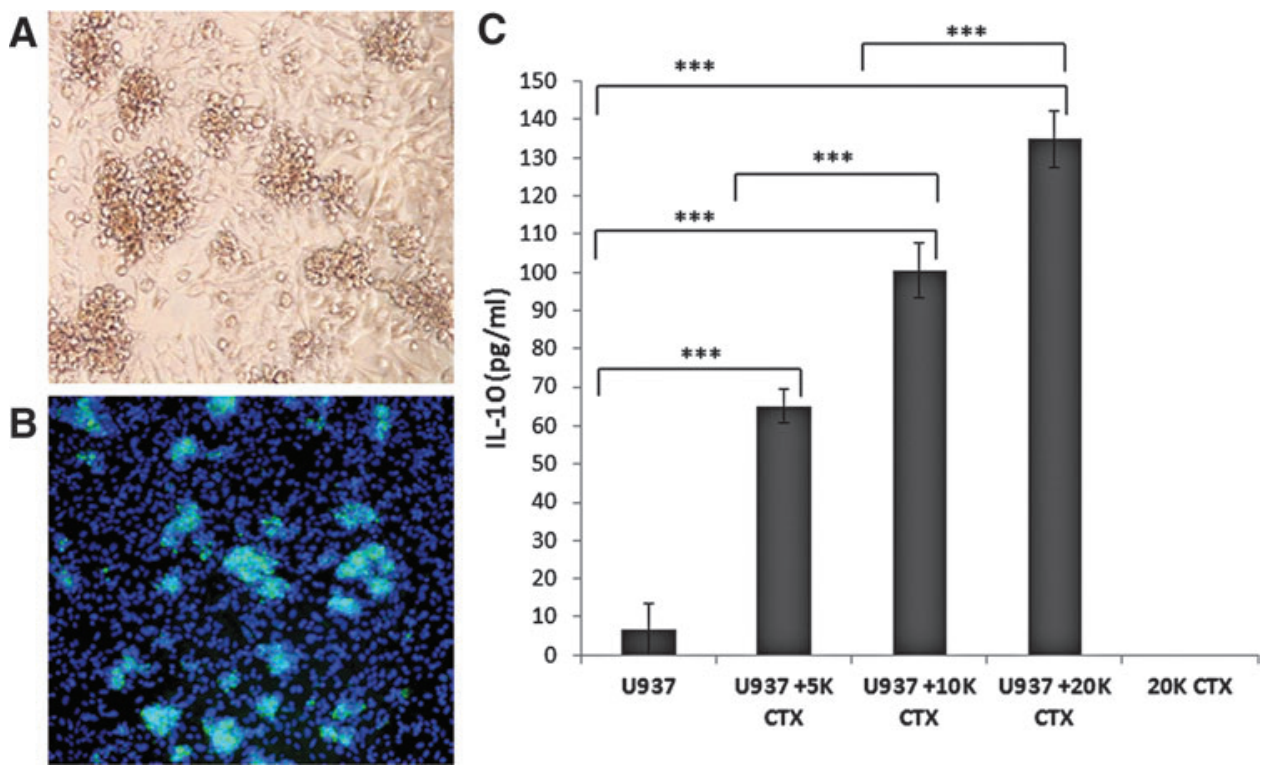

FIG. 2. Co-culture of CTX cells with activated U937 cells induces a concentration-dependent release of interleukin (IL)10 and expression of the M2 marker CD206. The assay requires cells from the mouse monocyte cell line U937, activated by using the phorbol ester, Phorbol 12-myristate 13-acetate (PMA) and the plating of CTX cells on prelaminin-coated 96-well plates at three different concentrations prior to their co-culture. The co-culture is established by adding the activated U937 cells at a fixed concentration (50,000 cells per well) to the attached CTX cells and then culturing for a period of $72 \mathrm{~h}$ (A). Immunocytochemical analysis of the co-cultures fixed at $72 \mathrm{~h}$ by using a human-specific anti-CD206 monoclonal antibody detected with anti-mouse Alexa Fluor 488 conjugated secondary antibody indicates the expression of CD206 (green), a marker of M2 polarization, by U937 cells visualized against a Hoechst nuclear counterstain (blue) (B). Culture media collected from each well at $72 \mathrm{~h}$ were analyzed for IL-10 concentration by using a human-specific ELISA (R\&D Systems). The data shown are mean \pm SEM $(n=3)$ from three independent cell samples in $\mathrm{pg} / \mathrm{mL}$; CTX cells in co-culture with U937 cells promote a statistically significant dose-dependent increase in IL-10 release compared with U937 cells cultured alone in a dose-dependent manner ( $* * * P \leq 0.001$ ANOVA) (C). 
rats [82]. PET studies indicate that there is a significant ischemic penumbra in humans, and that reversibly, ischemic tissue may persist for much longer than the initial experiments in animal models have suggested [83]. The functional recovery of the penumbra is the most clinically relevant target, and successful treatment would be aided by a local increase in $\mathrm{CBF}$ with the restoration of transport of soluble factors to the site of injury.

Human NSCs release VEGF in vitro [84], and they are known in vivo to restore $\mathrm{CBF}$ by promoting new blood vessel growth $[85,86]$. Previous studies that monitored blood flow in the lesioned hemisphere by using laser Doppler measurements postocclusion demonstrated a return of CBF to baseline levels 12-14 days after transient MCAo and MSCs implantation [87]. However, Ulrich et al. [88] followed CBF for 3 and 6 weeks after permanent MCAo and did not see a complete return to normal levels. Eve et al. [82], after examining both hemispheres, noted a difference in CBF between the left and right sides and a shifting in direction in a visual oscillatory fashion over time in control, sham-occluded, rats. This change in dominance between the left and right CBF suggested a natural oscillation of CBF in normal animals. In occluded animals, the laser Doppler measurements of CBF showed consistent left-side dominance. By 3 months after implantation, the CBF was observed to have improved in the lesioned hemisphere of the CTX-treated group compared with the untreated stroke rats and demonstrated a similar oscillatory nature as that seen in sham-occluded animals [82].

These findings support a regulated pro-angiogenic activity for CTX as one of its modes of action. Over the past years, several paracrine factors that play important roles in angiogenesis have been studied for their role in the angiogenic process, including VEGFA, basic FGF, and EGF [89,90]. Basic FGF and EGF promote angiogenesis by a direct effect on endothelial cells and indirectly by the upregulation of endothelial cell VEGFA [91]. VEGFA is an angiogenic growth factor, a potent mitogen, and a survival factor that is specific to endothelial cells [92,93], which has also demonstrated neuroprotective effects against ischemic injury [94-98]. CTX appears to perform a dual role in the promotion of angiogenesis in vitro: first, by the release of paracrine factors (VEGFA, EGF, bFGF, ANGPT1, TGFb1, HIF-1a, and ANGPT2); second, by direct physical cell interaction. In vitro, CTX treatment showed an increase in total tubule length formation compared with untreated controls [37].

In vivo, both MCAo and naive mouse brains demonstrated a clear increase in new host blood vessel formation, with CTX implantation using immunohistochemistry analysis (an antibody raised against VWF, an endothelial cell marker) [37]. In addition, BrdU/CD31 labeling in the naive mouse brain confirmed enhanced recruitment of proliferating endothelial progenitor cells and accelerated neo-vessel formation after CTX treatment. Human NSCs were found to be in precise association with blood vessels, suggesting the establishment of a "neurovascular niche" [37]. Within this type of niche, it is proposed that neural progenitor cells lie in close proximity to endothelial cells to induce angiogenesis and neurogenesis. Furthermore, endothelial cells can secrete soluble factors that regulate neuronal differentiation [69,99-101]. Moreover, CTX may support this effect by the local delivery of growth factors, including VEGF. The study data demonstrated that angiogenesis and neurogenesis may be considered coupled processes that are similar to those observed in a co-culture system employing neural progenitors and activated endothelial cells [81]. CTX can interact with vascular endothelial cells, specifically in areas of vascular remodeling, sprouting, and angiogenesis and ultimately aid repair (Fig. 3). These therapeutic benefits of CTX have also been demonstrated in ischemic muscles in the animal model of hind limb ischemia [102] and formed the basis for a United Kingdom clinical trial of CTX DP in lower-limb peripheral arterial disease (NCT01916369), which is currently underway.

\section{Recent Clinical Experience}

Of the more than 50 stem cell trials in ischemic stroke registered on the clinicaltrials.gov database, only two are investigating hNSCs, both CTX. The CTX Pilot Investigation of Human Neural Stem Cells in Chronic Ischemic Stroke Patients (PISCES) Phase I (NCT01151124) has been completed, and the locked trial data to 2 years have been published [9]. A follow-on Phase II efficacy trial (NCT02117635) has now completed patient recruitment.

\section{PISCES first-in human trial}

Translation of CTX stem cell therapy from the laboratory to the first-in-human trial in the United Kingdom has been approached with caution and based on rigorous preclinical studies in rats with chronic stroke, which showed improvements in behavioral outcomes and indicated long-term safety [33]. The PISCES trial was designed as an open dose-escalation study, in which men aged 60 years or older with stable chronic stroke received single doses of $2,5,10$, or 20 million CTX-DP cells by stereotactic ipsilateral putamen injection [9]. The primary objective of the trial was to assess the safety and tolerability of intracerebral transplantation of CTX and second, to observe neurological and functional outcomes over the 24 months after treatment. There were no cell-related adverse events. Serious adverse events (SAEs) related to the procedure were noted from imaging in 4 out of 11 patients, but none were symptomatic, a finding consistent with general safety data for brain stereotactic procedures $[103,104]$. No incidence of seizures was recorded, unlike previous trials in which teratocarcinomaderived neuronal cells [105,106] and fetal porcine cells [107] were implanted to treat stroke.

The secondary endpoints monitored were exploratory indices of efficacy, using modified Rankin Scale (mRS), NIH stroke scale (NIHSS), Ashworth Scale for upper- and lowerlimb spasticity, and Barthel Index of activities of daily living (BI). After CTX-DP implantation, statistically significant improvements were seen over time in NIHSS, and nonsignificant improvements were observed in summed arm and leg Ashworth scale and BI scores [9]. Disability, as measured by the $\mathrm{mRS}$, at 12 months was unchanged in 7 out of 11 patients and improved by one grade in 4 . At 24 months, disability was unchanged in seven patients, worsened by two grades in one patient, and improved by one grade in three patients. Patients who reported overall health status had improved by a median of 18 points (interquartile range -5 to 30 ) at 12 months compared with baseline. Functional magnetic resonance imaging (fMRI) data were also collected pre- and post-treatment to identify potential biomarkers of change in neurological function in the brains of the treated patients. Some longitudinal changes in 


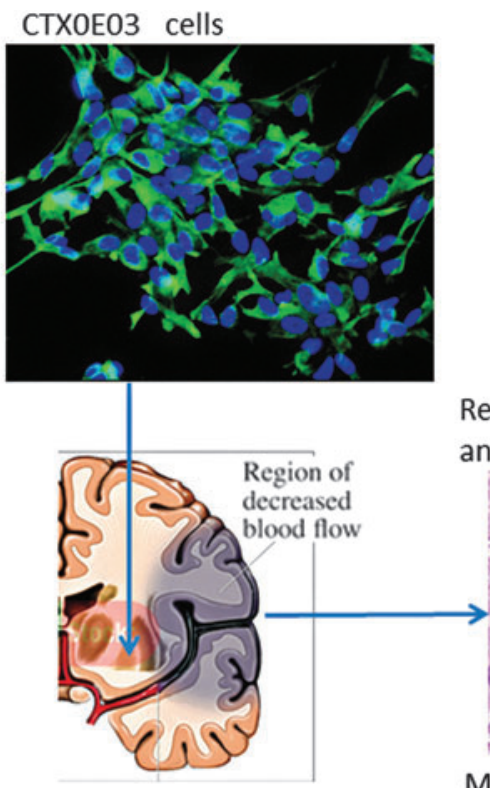

Cells implanted in the putamen near the area of stroke damage....

\section{CTXOEO3}

Mechanisms

of Action

Release growth factors and cytokines....

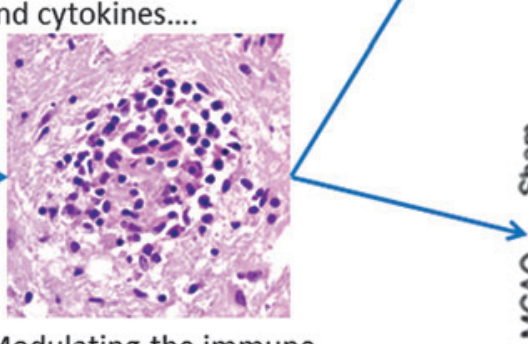

Modulating the immune system from an inflammatory

to a repair promoting phenotype, leading to....

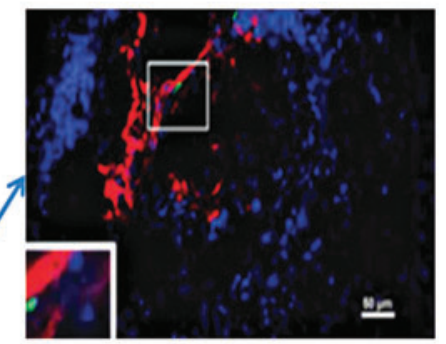

Formation of new blood vessels (angiogenesis)

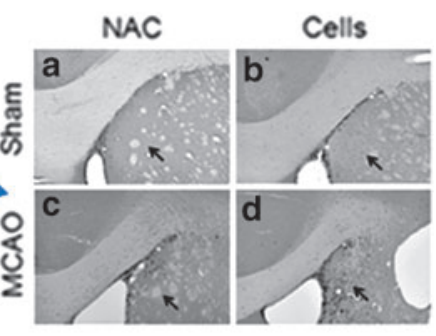

Formation of new neurons (neurogenesis)

FIG. 3. Summary of CTX mechanisms of action in ischemic stroke. CTX cells are stored in a frozen state and thawed just prior to use. No further processing is required prior to administration. Cells are administered via stereotaxic intracerebral injection into an area adjacent to stroke damage that has maintained blood flow (putamen). Neuronal cell replacement/ engraftment was hypothesized to be the most obvious mechanism of action, whereas the observed pharmacokinetics of CTX cells does not support this theory. CTX cells may exert their therapeutic effect by paracrine mechanisms. Upregulation of VEGFA and chemokines CCL2 and CXCL12 suggests that these may be candidate factors. In vivo, CTX treatment promotes recruitment, proliferation, and/or maintenance of host cell populations, including immune and stromal cells, neural progenitor and endothelial progenitor cell types. In vitro, CTX cells demonstrate immunomodulatory activity by promoting polarization of U937 cells from a pro-inflammatory to an alternative anti-inflammatory CD206, IL-10-producing phenotype commonly associated with tissue remodeling and repair. Angiogenesis is promoted by CTX administration. CTX cell implantation restores von Willebrand Factor (a marker of angiogenesis) in the lesioned hemisphere to a level comparable with control (nonlesioned) tissue. Evidence of angiogenesis was demonstrated by de novo blood vessel formation and increased blood flow in the affected hemisphere in rat transient MCAo postimplantation. Analysis of treated brain sections shows that implantation of CTX cells into the MCAo brain returns host cell proliferation in the subventricular zone to a similar level to that seen in sham-lesioned controls. CTX administration also increases the presence of proliferating microglia and neuroblasts in the striatum. MCAo, middle cerebral artery occlusion; NAC, n-acetylcysteine.

motor activation fMRI were seen, consistent with the improvements in neurological measures.

Due to the small number of patients treated in the trial, their heterogeneity as a study population, and the open-label, single-arm study design, it is not possible to draw reliable conclusions about the effects of CTX cell implantation on neurological or functional recovery. However, it was possible to note that despite the selection of chronic, stable patients at late stages after stroke, most showed some improvement across several indices of function [9]. Whether attributable to cell implantation or to other factors, such as extra medical attention, a change in this patient group suggests that trials of interventions are worthwhile late after stroke, when recovery is not generally believed to be attainable. The researchers also described anecdotal accounts of reduced spasticity, minor return of finger movement at phalangeal joints, and improved visual perception and better bed-tochair transfers, which were supported by the changes in health-related quality of life, activities of daily living, and neurological impairment [9].
In this first trial, only men were enrolled, given the early nature of stem cell clinical research and the lack of reproductive toxicology outcomes for stem cells of any origin and, in particular, for CTX, in which a tamoxifen metabolite analogue receptor is used in vitro to control cell manufacture [25]. Subsequent studies, however, are not limited to men as further preclinical studies did not show any tumor formation or increased CTX proliferation in male and female stroke rats chronically treated with tamoxifen.

Patients were not given immunosuppressive therapy because nonclinical studies with CTX showed no evidence that cell survival and efficacy required immunosuppression [33]. In addition, in vitro studies for MHC class II (DR) and MHC class I (A, B, and C) showed low protein expression for CTX [9]. Further, immunosuppressive therapy heightens the risk of infection after stroke, which is independently associated with poor outcomes. The putamen was chosen as the site for implantation based on preclinical data, which defined it as the closest intact subcortical neuronal cluster to the lesion and for its preference to white matter, in which 
injections can cause further axonal injury related to increased pressure. We selected CTX-DP doses by scaling up from those that were efficacious in rats, and the ascending dose design (from 2 to 20 million cells) allowed cautious incremental increases after safety review. All patients received short- and long-term safety reviews and will be followed life-long for cancer.

In parallel, SanBio Inc in the United States is undertaking a clinical development program with a Notch-1 modified MSC line, SB623 in similar chronically disabled stroke patients. Recently, the Phase I outcomes from a U.S. multicenter trial were reported [108] and showed similar improvements in NIHSS over time, with other measures employed in that study also showing some improvements. No SAEs were attributable to the cell therapy $[109,110]$.

\section{PISCES Phase II efficacy trial}

Based on an early demonstration of safety and feasibility in the Phase I trial, PISCES Phase II is following suit, to assess the safety and efficacy of intracerebral CTX-DP in patients with paresis of an arm after an ischemic MCA stroke. The trial design is a UK multicenter, open-label, single-arm, noncomparative design, administering a single dose of 20 million cells 3 months postischemic stroke with follow-up over 12 months. Eligible patients, men or women aged 40 years or older, who have no useful function of the paretic arm for a minimum of 3 months to a maximum of 12 months after the ischemic stroke qualify to enroll into a minimum cohort of 21 patients. The design will determine whether a sufficient proportion of patients experience recovery of function with CTX-DP at a dose level of 20 million cells (maximum dose from the Phase I) to justify a subsequent larger prospectively randomized efficacy study. Endpoint measures will include recovery of useful upper-limb movement based on, for example, changes in the action research arm test [111], as well as established neurological and disability scales, such as NIHSS, a more objective version of mRS, Rankin Focused Assessment, and BI at 3, 6, and 12 months post-treatment.

\section{Future Clinical Aspects}

The PISCES Phase I trial results demonstrated the feasibility of intracerebrally administered CTX-DP therapy and safety in elderly severely disabled men with chronic stroke. Due to its open trial design and the small number and heterogeneity of patients treated, it is not possible to draw a reliable conclusion about the effects of hNSC therapy on neurological or functional recovery; although improvements were noted despite the selection of chronic, stable patients at late stages after stroke [9].

Phase II studies address methodologies and investigate biological evidence of activity to progress to pivotal trial data. The STEPS 3 guidelines recommend a Phase II study design, which, along with standard measures of functional disability and activities of daily life, include domain-specific endpoints assessing the recovery of sensory, motor, visual, and cognitive functions by using validated measures [112]. A desirable goal for a stroke-disabled patient would be to achieve a level of functional independence that would enable them to return home and reintegrate into community life as fully as possible. Hemiparesis and motor recovery have been the most studied of all stroke impairments, affecting as many as $88 \%$ of patients acutely poststroke. A systematic review of 58 studies confirms that the most important predictive factor for upperlimb recovery after stroke is the initial severity of motor impairment or function [113]. The prognosis for return of useful hand function is unfavorable when upper-arm paralysis is complete at onset or grasp strength is not measurable by 4 weeks, with most recovery taking place in the first 3 months with little further recovery thereafter. This suggests that 3 months is the earliest time point for an invasive stem cell intervention.

The determination of clinical efficacy requires an appropriately designed and controlled study. However, appropriate controls for a randomized trial are likely to be a compromise in some respects. Historical controls are not valid, and concurrent controls who undergo only conventional medical and rehabilitation therapies are also sub-optimal, since they are not exposed to the invasive procedures and the potent placebo effect of "stem cell therapy" [114]. Although essential scientifically, placebo (or "sham") neurosurgery is of uncertain acceptability to patients, and the need for sham neurosurgery has been challenged by patient groups [115]. Patient acceptability of the design of a proposed trial is essential to ensure recruitment, and rigid adherence to conventional parallelgroup randomized controlled trial designs is difficult at the early stages of efficacy testing, since patients who accept the risks of surgery and experimental treatment are frequently unwilling to consider the possibility that they will be randomly allocated to a placebo control group [116]. The rewardrisk balance for neurosurgical administration may also necessitate the use of clinically (not just statistically) significant endpoints in a relatively small number of patients, which poses a major challenge.

The ability to adjust for concomitant rehabilitation therapy in both active and control arms represents a difficulty in trial design. It is also possible that rehabilitation training is a necessary facilitation factor for regenerative effects of cell therapies to be seen, although animal models of nonspecific physical therapies suggest that negative interactions are also possible. Implementation of standardized therapy as part of a clinical trial is difficult when dealing with what is traditionally a highly individualized and time-limited intervention that varies widely across healthcare systems.

\section{Author Disclosure Statement}

J.S., C.H., P.S., and R.C. are employees of and stock and/ or option holders in ReNeuron. I.V. received financial support from ReNeuron for her assistance in drafting and preparing this article for publication.

\section{References}

1. Sinden JD, I Vishnubhatla and KW Muir. (2012). Prospects for stem cell-derived therapy in stroke. Prog Brain Res 201:119-167.

2. Hermann DM and M Chopp. (2012). Promoting brain remodelling and plasticity for stroke recovery: therapeutic promise and potential pitfalls of clinical translation. Lancet Neurol 11:369-380.

3. Loubinoux I, B Demain, C Davoust, B Plas and L Vaysse. (2014). Stem cells and motor recovery after stroke. Ann Phys Rehabil Med 57:499-508. 
4. Miljan EA and JD Sinden. (2009). Stem cell treatment of ischemic brain injury. Curr Opin Mol Ther 11:394-403.

5. Burns TC and CM Verfaillie. (2015). From mice to mind: strategies and progress in translating neuroregeneration. Eur J Pharmacol 759:90-100.

6. Dulamea AO. (2015). The potential use of mesenchymal stem cells in stroke therapy-from bench to bedside. J Neurol Sci 352:1-11.

7. Ye X, J Hu and G Cui. (2016). Therapy Effects of Bone Marrow Stromal Cells on Ischemic Stroke. Oxid Med Cell Longev 2016:7682960.

8. Hu J, B Liu, Q Zhao, P Jin, F Hua, Z Zhang, Y Liu, K Zan, G Cui and X Ye. (2016). Bone marrow stromal cells inhibits HMGB1-mediated inflammation after stroke in type 2 diabetic rats. Neuroscience 324:11-19.

9. Kalladka D, J Sinden, K Pollock, C Haig, J McLean, W Smith, A McConnachie, C Santosh, PM Bath, L Dunn and KW Muir. (2016). Human neural stem cells in patients with chronic ischaemic stroke (PISCES): a phase 1, firstin-man study. Lancet 388:787-796.

10. Pollock K and J Sinden. (2008). Chapter 6. Progressing neural stem cell lines to the clinic. In: Stem Cell Research and Therapeutics. Shi Y, D Clegg, eds. Springer, Netherlands, pp 105-122.

11. Netto CA, H Hodges, JD Sinden, E LePeillet, T Kershaw, P Sowinski, BS Meldrum and JA Gray. (1993). Foetal grafts from hippocampal regio superior alleviate ischaemicinduced behavioural deficits. Behav Brain Res 58:107-112.

12. Nunn J and H Hodges. (1994). Cognitive deficits induced by global cerebral ischaemia: relationship to brain damage and reversal by transplants. Behav Brain Res 65:1-31.

13. Olanow CW, CG Goetz, JH Kordower, AJ Stoessl, V Sossi, MF Brin, KM Shannon, GM Nauert, DP Perl, J Godbold and TB Freeman. (2003). A double-blind controlled trial of bilateral fetal nigral transplantation in Parkinson's disease. Ann Neurol 54:403-414.

14. Villa A, EY Snyder, A Vescovi and A Martinez-Serrano. (2000). Establishment and properties of a growth factordependent, perpetual neural stem cell line from the human CNS. Exp Neurol 161:67-84.

15. Wright LS, KR Prowse, K Wallace, MH Linskens and CN Svendsen. (2006). Human progenitor cells isolated from the developing cortex undergo decreased neurogenesis and eventual senescence following expansion in vitro. Exp Cell Res 312:2107-2120.

16. Donato R, EA Miljan, SJ Hines, S Aouabdi, K Pollock, S Patel, FA Edwards and JD Sinden. (2007). Differential development of neuronal physiological responsiveness in two human neural stem cell lines. BMC Neurosci 8:36.

17. Villa A, B Navarro-Galve, C Bueno, S Franco, MA Blasco and A Martinez-Serrano. (2004). Long-term molecular and cellular stability of human neural stem cell lines. Exp Cell Res 294:559-570.

18. Hodges H, K Pollock, P Stroemer, S Patel, L Stevanato, I Reuter and J Sinden. (2007). Making stem cell lines suitable for transplantation. Cell Transplant 16:101-115.

19. Dang CV, LM Resar, E Emison, S Kim, Q Li, JE Prescott, D Wonsey and K Zeller. (1999). Function of the c-Myc oncogenic transcription factor. Exp Cell Res 253:63-77.

20. Kim SU. (2004). Human neural stem cells genetically modified for brain repair in neurological disorders. Neuropathology 24:159-171.

21. Li Z, D Oganesyan, R Mooney, X Rong, MJ Christensen, D Shahmanyan, PM Perrigue, J Benetatos, L Tsaturyan, et al. (2016). L-MYC Expression maintains self-renewal and prolongs multipotency of primary human neural stem cells. Stem Cell Reports 7:483-495.

22. Takahashi K and S Yamanaka. (2006). Induction of pluripotent stem cells from mouse embryonic and adult fibroblast cultures by defined factors. Cell 126:663-676.

23. Pollock K, P Stroemer, S Patel, L Stevanato, A Hope, E Miljan, Z Dong, H Hodges, J Price and JD Sinden. (2006). A conditionally immortal clonal stem cell line from human cortical neuroepithelium for the treatment of ischemic stroke. Exp Neurol 199:143-155.

24. Littlewood TD, DC Hancock, PS Danielian, MG Parker and GI Evan. (1995). A modified oestrogen receptor ligandbinding domain as an improved switch for the regulation of heterologous proteins. Nucleic Acids Res 23:1686-1690.

25. Stevanato L, RL Corteling, P Stroemer, A Hope, J Heward, EA Miljan and JD Sinden. (2009). c-MycERTAM transgene silencing in a genetically modified human neural stem cell line implanted into MCAo rodent brain. BMC Neurosci 10:86.

26. Thomas RJ, AD Hope, P Hourd, M Baradez, EA Miljan, JD Sinden and DJ Williams. (2009). Automated, serum-free production of CTX0E03: a therapeutic clinical grade human neural stem cell line. Biotechnol Lett 31:1167-1172.

27. Modo M, RP Stroemer, E Tang, T Veizovic, P Sowniski and $\mathrm{H}$ Hodges. (2000). Neurological sequelae and longterm behavioural assessment of rats with transient middle cerebral artery occlusion. J Neurosci Methods 104:99-109.

28. Schallert T. (2006). Behavioral tests for preclinical intervention assessment. NeuroRx 3:497-504.

29. Muir KW and JD Sinden. (2015). The CTX human neural stem cell line and the PISCES stroke trial. In: Cell Therapy for Brain Injury. Hess DC, ed. Springer, Switzerland, pp 111-128.

30. Laing RJ, J Jakubowski and RW Laing. (1993). Middle cerebral artery occlusion without craniectomy in rats. Which method works best? Stroke 24:294-297; discussion 297-298.

31. Virley D. (2005). Choice, methodology, and characterization of focal ischemic stroke models: the search for clinical relevance. Methods Mol Med 104:19-48.

32. Longa EZ, PR Weinstein, S Carlson and R Cummins. (1989). Reversible middle cerebral artery occlusion without craniectomy in rats. Stroke 20:84-91.

33. Stroemer P, S Patel, A Hope, C Oliveira, K Pollock and J Sinden. (2009). The neural stem cell line CTX0E03 promotes behavioral recovery and endogenous neurogenesis after experimental stroke in a dose-dependent fashion. Neurorehabil Neural Repair 23:895-909.

34. Smith EJ, RP Stroemer, N Gorenkova, M Nakajima, WR Crum, E Tang, L Stevanato, JD Sinden and M Modo. (2012). Implantation site and lesion topology determine efficacy of a human neural stem cell line in a rat model of chronic stroke. Stem Cells 30:785-796.

35. Bliss T, R Guzman, M Daadi and GK Steinberg. (2007). Cell transplantation therapy for stroke. Stroke 38:817-826.

36. Hassani Z, J O'Reilly, Y Pearse, P Stroemer, E Tang, J Sinden, J Price and S Thuret. (2012). Human neural progenitor cell engraftment increases neurogenesis and microglial recruitment in the brain of rats with stroke. PLoS One 7:e50444.

37. Hicks C, L Stevanato, RP Stroemer, E Tang, S Richardson and JD Sinden. (2013). In vivo and in vitro characterization of the angiogenic effect of CTX0E03 human neural stem cells. Cell Transplant 22:1541-1552. 
38. Ryu S, SH Lee, SU Kim and BW Yoon. (2016). Human neural stem cells promote proliferation of endogenous neural stem cells and enhance angiogenesis in ischemic rat brain. Neural Regen Res 11:298-304.

39. Jin K, L Xie, X Mao, MB Greenberg, A Moore, B Peng, RB Greenberg and DA Greenberg. (2011). Effect of human neural precursor cell transplantation on endogenous neurogenesis after focal cerebral ischemia in the rat. Brain Res 1374:56-62.

40. Darsalia V, SJ Allison, C Cusulin, E Monni, D Kuzdas, T Kallur, O Lindvall and Z Kokaia. (2011). Cell number and timing of transplantation determine survival of human neural stem cell grafts in stroke-damaged rat brain. J Cereb Blood Flow Metab 31:235-242.

41. Andres RH, N Horie, W Slikker, H Keren-Gill, K Zhan, G Sun, NC Manley, MP Pereira, LA Sheikh, et al. (2011). Human neural stem cells enhance structural plasticity and axonal transport in the ischaemic brain. Brain 134:17771789.

42. Darsalia V, T Kallur and Z Kokaia. (2007). Survival, migration and neuronal differentiation of human fetal striatal and cortical neural stem cells grafted in strokedamaged rat striatum. Eur J Neurosci 26:605-614.

43. Daadi MM, AS Davis, A Arac, Z Li, AL Maag, R Bhatnagar, K Jiang, G Sun, JC Wu and GK Steinberg. (2010). Human neural stem cell grafts modify microglial response and enhance axonal sprouting in neonatal hypoxicischemic brain injury. Stroke 41:516-523.

44. Mine Y, J Tatarishvili, K Oki, E Monni, Z Kokaia and O Lindvall. (2013). Grafted human neural stem cells enhance several steps of endogenous neurogenesis and improve behavioral recovery after middle cerebral artery occlusion in rats. Neurobiol Dis 52:191-203.

45. Kelly S, TM Bliss, AK Shah, GH Sun, M Ma, WC Foo, J Masel, MA Yenari, IL Weissman, et al. (2004). Transplanted human fetal neural stem cells survive, migrate, and differentiate in ischemic rat cerebral cortex. Proc Natl Acad Sci U S A 101:11839-11844.

46. Hicks AU, RS Lappalainen, S Narkilahti, R Suuronen, D Corbett, J Sivenius, O Hovatta and J Jolkkonen. (2009). Transplantation of human embryonic stem cell-derived neural precursor cells and enriched environment after cortical stroke in rats: cell survival and functional recovery. Eur J Neurosci 29:562-574.

47. Park DH, DJ Eve, PR Sanberg, J Musso, 3rd, AD Bachstetter, A Wolfson, A Schlunk, MO Baradez, JD Sinden and C Gemma. (2010). Increased neuronal proliferation in the dentate gyrus of aged rats following neural stem cell implantation. Stem Cells Dev 19:175-180.

48. Arvidsson A, T Collin, D Kirik, Z Kokaia and O Lindvall. (2002). Neuronal replacement from endogenous precursors in the adult brain after stroke. Nat Med 8:963-970.

49. Zhang P, J Li, Y Liu, X Chen, H Lu, Q Kang, W Li and M Gao. (2011). Human embryonic neural stem cell transplantation increases subventricular zone cell proliferation and promotes peri-infarct angiogenesis after focal cerebral ischemia. Neuropathology 31:384-391.

50. Sullivan R, K Duncan, T Dailey, Y Kaneko, N Tajiri and CV Borlongan. (2015). A possible new focus for stroke treatment-migrating stem cells. Expert Opin Biol Ther 15:949-958.

51. Tajiri N, Y Kaneko, K Shinozuka, H Ishikawa, E Yankee, M McGrogan, C Case and CV Borlongan. (2013). Stem cell recruitment of newly formed host cells via a successful seduction? Filling the gap between neurogenic niche and injured brain site. PLoS One 8:e74857.

52. Gnecchi M, Z Zhang, A Ni and VJ Dzau. (2008). Paracrine mechanisms in adult stem cell signaling and therapy. Circ Res 103:1204-1219.

53. Bliss TM, S Kelly, AK Shah, WC Foo, P Kohli, C Stokes, GH Sun, M Ma, J Masel, et al. (2006). Transplantation of hNT neurons into the ischemic cortex: cell survival and effect on sensorimotor behavior. J Neurosci Res 83:1004-1014.

54. Chu K, M Kim, KI Park, SW Jeong, HK Park, KH Jung, ST Lee, L Kang, K Lee, et al. (2004). Human neural stem cells improve sensorimotor deficits in the adult rat brain with experimental focal ischemia. Brain Res 1016:145-153.

55. Jiang Q, ZG Zhang, GL Ding, B Silver, L Zhang, H Meng, M Lu, DS Pourabdillah-Nejed, L Wang, et al. (2006). MRI detects white matter reorganization after neural progenitor cell treatment of stroke. Neuroimage 32:1080-1089.

56. Daadi MM, Z Li, A Arac, BA Grueter, M Sofilos, RC Malenka, JC Wu and GK Steinberg. (2009). Molecular and magnetic resonance imaging of human embryonic stem cell-derived neural stem cell grafts in ischemic rat brain. Mol Ther 17:1282-1291.

57. Locatelli F, A Bersano, E Ballabio, S Lanfranconi, D Papadimitriou, S Strazzer, N Bresolin, GP Comi and S Corti. (2009). Stem cell therapy in stroke. Cell Mol Life Sci 66:757-772.

58. Shen CC, CH Lin, YC Yang, MT Chiao, WY Cheng and JL Ko. (2010). Intravenous implanted neural stem cells migrate to injury site, reduce infarct volume, and improve behavior after cerebral ischemia. Curr Neurovasc Res 7:167-179.

59. Madhavan L, BF Daley, KL Paumier and TJ Collier. (2009). Transplantation of subventricular zone neural precursors induces an endogenous precursor cell response in a rat model of Parkinson's disease. J Comp Neurol 515:102-115.

60. Maurer MH, WK Tripps, RE Feldmann, Jr. and W Kuschinsky. (2003). Expression of vascular endothelial growth factor and its receptors in rat neural stem cells. Neurosci Lett 344:165-168.

61. Kalyani AJ, T Mujtaba and MS Rao. (1999). Expression of EGF receptor and FGF receptor isoforms during neuroepithelial stem cell differentiation. J Neurobiol 38:207-224.

62. Morshead CM, BA Reynolds, CG Craig, MW McBurney, WA Staines, D Morassutti, S Weiss and D van der Kooy. (1994). Neural stem cells in the adult mammalian forebrain: a relatively quiescent subpopulation of subependymal cells. Neuron 13:1071-1082.

63. Ekdahl CT, JH Claasen, S Bonde, Z Kokaia and O Lindvall. (2003). Inflammation is detrimental for neurogenesis in adult brain. Proc Natl Acad Sci U S A 100:13632-13637.

64. Parent JM, ZS Vexler, C Gong, N Derugin and DM Ferriero. (2002). Rat forebrain neurogenesis and striatal neuron replacement after focal stroke. Ann Neurol 52:802-813.

65. Zhang RL, ZG Zhang, Y Wang, Y LeTourneau, XS Liu, X Zhang, SR Gregg, L Wang and M Chopp. (2007). Stroke induces ependymal cell transformation into radial glia in the subventricular zone of the adult rodent brain. J Cereb Blood Flow Metab 27:1201-1212.

66. Garcia-Verdugo JM, F Doetsch, H Wichterle, DA Lim and A Alvarez-Buylla. (1998). Architecture and cell types of the adult subventricular zone: in search of the stem cells. J Neurobiol 36:234-248.

67. Horie N, MP Pereira, K Niizuma, G Sun, H Keren-Gill, A Encarnacion, M Shamloo, SA Hamilton, K Jiang, et al. 
(2011). Transplanted stem cell-secreted vascular endothelial growth factor effects poststroke recovery, inflammation, and vascular repair. Stem Cells 29:274-285.

68. Aggarwal S and MF Pittenger. (2005). Human mesenchymal stem cells modulate allogeneic immune cell responses. Blood 105:1815-1822.

69. Shen Q, SK Goderie, L Jin, N Karanth, Y Sun, N Abramova, P Vincent, K Pumiglia and S Temple. (2004). Endothelial cells stimulate self-renewal and expand neurogenesis of neural stem cells. Science 304:1338-1340.

70. Chen TS, F Arslan, Y Yin, SS Tan, RC Lai, AB Choo, J Padmanabhan, CN Lee, DP de Kleijn and SK Lim. (2011). Enabling a robust scalable manufacturing process for therapeutic exosomes through oncogenic immortalization of human ESC-derived MSCs. J Transl Med 9:47.

71. Shieh DE, LT Liu and CC Lin. (2000). Antioxidant and free radical scavenging effects of baicalein, baicalin and wogonin. Anticancer Res 20:2861-2865.

72. Perez CA, Y Wei and M Guo. (2009). Iron-binding and anti-Fenton properties of baicalein and baicalin. J Inorg Biochem 103:326-332.

73. Munn DH and AL Mellor. (2013). Indoleamine 2,3 dioxygenase and metabolic control of immune responses. Trends Immunol 34:137-143.

74. Chen S, R Corteling, L Stevanato and J Sinden. (2012). Natural inhibitors of indoleamine 3,5-dioxygenase induced by interferon-gamma in human neural stem cells. Biochem Biophys Res Commun 429:117-123.

75. David S and A Kroner. (2011). Repertoire of microglial and macrophage responses after spinal cord injury. Nat Rev Neurosci 12:388-399.

76. Mantovani A, A Sica and M Locati. (2007). New vistas on macrophage differentiation and activation. Eur J Immunol 37:14-16.

77. Capone C, S Frigerio, S Fumagalli, M Gelati, MC Principato, C Storini, M Montinaro, R Kraftsik, M De Curtis, E Parati and MG De Simoni. (2007). Neurosphere-derived cells exert a neuroprotective action by changing the ischemic microenvironment. PLoS One 2:e373.

78. Lalancette-Hebert M, G Gowing, A Simard, YC Weng and J Kriz. (2007). Selective ablation of proliferating microglial cells exacerbates ischemic injury in the brain. J Neurosci 27:2596-2605.

79. Ernst A, K Alkass, S Bernard, M Salehpour, S Perl, J Tisdale, G Possnert, H Druid and J Frisen. (2014). Neurogenesis in the striatum of the adult human brain. Cell 156:1072-1083.

80. Arenillas JF, T Sobrino, J Castillo and A Davalos. (2007). The role of angiogenesis in damage and recovery from ischemic stroke. Curr Treat Options Cardiovasc Med 9:205-212.

81. Slevin M, J Krupinski, J Gaffney, S Matou, D West, H Delisser, RC Savani and S Kumar. (2007). Hyaluronanmediated angiogenesis in vascular disease: uncovering RHAMM and CD44 receptor signaling pathways. Matrix Biol 26:58-68.

82. Eve DJ, J Musso, 3rd, DH Park, C Oliveira, K Pollock, A Hope, MO Baradez, JD Sinden and PR Sanberg. (2009). Methodological study investigating long term laser Doppler measured cerebral blood flow changes in a permanently occluded rat stroke model. J Neurosci Methods 180:52-56.

83. Markus R, G Donnan, S Kazui, S Read and D Reutens. (2004). Penumbral topography in human stroke: methodology and validation of the 'Penumbragram'. Neuroimage 21:1252-1259.
84. Eve DJ, IJ Musso, VH Bui, AJ Smith, C Gemma, DF Cameron, C Oliveira, K Pollock, A Hope, et al. (2008). Release of VEGF by ReN001 cortical stem cells. Cell Transplant 17:464-465.

85. Li Y, Z Lu, CL Keogh, SP Yu and L Wei. (2007). Erythropoietin-induced neurovascular protection, angiogenesis, and cerebral blood flow restoration after focal ischemia in mice. J Cereb Blood Flow Metab 27:10431054.

86. Mathe Z, P Dupraz, C Rinsch, B Thorens, D Bosco, M Zbinden, P Morel, T Berney and MS Pepper. (2006). Tetracycline-regulated expression of VEGF-A in beta cells induces angiogenesis: improvement of engraftment following transplantation. Cell Transplant 15:621-636.

87. Borlongan CV, JG Lind, O Dillon-Carter, G Yu, M Hadman, C Cheng, J Carroll and DC Hess. (2004). Bone marrow grafts restore cerebral blood flow and blood brain barrier in stroke rats. Brain Res 1010:108-116.

88. Ulrich PT, S Kroppenstedt, A Heimann and O Kempski. (1998). Laser-Doppler scanning of local cerebral blood flow and reserve capacity and testing of motor and memory functions in a chronic 2-vessel occlusion model in rats. Stroke 29:2412-2420.

89. Diaz-Flores L, R Gutierrez and H Varela. (1994). Angiogenesis: an update. Histol Histopathol 9:807-843.

90. Folkman J and M Klagsbrun. (1987). Angiogenic factors. Science 235:442-447.

91. Kawasuji M, H Nagamine, M Ikeda, N Sakakibara, H Takemura, S Fujii and Y Watanabe. (2000). Therapeutic angiogenesis with intramyocardial administration of basic fibroblast growth factor. Ann Thorac Surg 69: 1155-1161.

92. Gerber HP, A McMurtrey, J Kowalski, M Yan, BA Keyt, V Dixit and N Ferrara. (1998). Vascular endothelial growth factor regulates endothelial cell survival through the phosphatidylinositol 3'-kinase/Akt signal transduction pathway. Requirement for Flk-1/KDR activation. J Biol Chem 273:30336-30343.

93. Lu J, VJ Pompili and H Das. (2013). Neovascularization and hematopoietic stem cells. Cell Biochem Biophys 67:235-245.

94. Harrigan MR, SR Ennis, SE Sullivan and RF Keep. (2003). Effects of intraventricular infusion of vascular endothelial growth factor on cerebral blood flow, edema, and infarct volume. Acta Neurochir (Wien) 145:49-53.

95. Hayashi T, K Abe and Y Itoyama. (1998). Reduction of ischemic damage by application of vascular endothelial growth factor in rat brain after transient ischemia. J Cereb Blood Flow Metab 18:887-895.

96. Kaya D, Y Gursoy-Ozdemir, M Yemisci, N Tuncer, S Aktan and T Dalkara. (2005). VEGF protects brain against focal ischemia without increasing blood-brain permeability when administered intracerebroventricularly. J Cereb Blood Flow Metab 25:1111-1118.

97. Sun Y, K Jin, L Xie, J Childs, XO Mao, A Logvinova and DA Greenberg. (2003). VEGF-induced neuroprotection, neurogenesis, and angiogenesis after focal cerebral ischemia. J Clin Invest 111:1843-1851.

98. Zhang ZG, L Zhang, Q Jiang, R Zhang, K Davies, C Powers, N Bruggen and M Chopp. (2000). VEGF enhances angiogenesis and promotes blood-brain barrier leakage in the ischemic brain. J Clin Invest 106:829-838.

99. Alvarez-Buylla A and DA Lim. (2004). For the long run: maintaining germinal niches in the adult brain. Neuron 41:683-686. 
100. Ohab JJ, S Fleming, A Blesch and ST Carmichael. (2006). A neurovascular niche for neurogenesis after stroke. J Neurosci 26:13007-13016.

101. Wurmser AE, TD Palmer and FH Gage. (2004). Neuroscience. Cellular interactions in the stem cell niche. Science 304:1253-1255.

102. Katare R, P Stroemer, C Hicks, L Stevanato, S Patel, R Corteling, E Miljan, I Vishnubhatla, J Sinden and P Madeddu. (2014). Clinical-grade human neural stem cells promote reparative neovascularization in mouse models of hindlimb ischemia. Arterioscler Thromb Vasc Biol 34: 408-418.

103. Favre J, JM Taha and KJ Burchiel. (2002). An analysis of the respective risks of hematoma formation in 361 consecutive morphological and functional stereotactic procedures. Neurosurgery 50:48-56; discussion 56-57.

104. Muir KW, J Sinden, E Miljan and L Dunn. (2011). Intracranial delivery of stem cells. Transl Stroke Res 2:266271.

105. Kondziolka D, GK Steinberg, L Wechsler, CC Meltzer, E Elder, J Gebel, S Decesare, T Jovin, R Zafonte, et al. (2005). Neurotransplantation for patients with subcortical motor stroke: a phase 2 randomized trial. J Neurosurg 103:38-45.

106. Kondziolka D, L Wechsler, S Goldstein, C Meltzer, KR Thulborn, J Gebel, P Jannetta, S DeCesare, EM Elder, et al. (2000). Transplantation of cultured human neuronal cells for patients with stroke. Neurology 55:565-569.

107. Savitz SI, J Dinsmore, J Wu, GV Henderson, P Stieg and LR Caplan. (2005). Neurotransplantation of fetal porcine cells in patients with basal ganglia infarcts: a preliminary safety and feasibility study. Cerebrovasc Dis 20:101-107.

108. Steinberg GK, D Kondziolka, LR Wechsler, LD Lunsford, ML Coburn, JB Billigen, AS Kim, JN Johnson, D Bates, et al. (2016). Clinical outcomes of transplanted modified bone marrow-derived mesenchymal stem cells in stroke: a phase 1/2a study. Stroke 47:1817-1824.

109. Borlongan CV. (2016). Preliminary reports of stereotaxic stem cell transplants in chronic stroke patients. Mol Ther 24:1710-1711.

110. Borlongan CV. (2016). Age of PISCES: stem-cell clinical trials in stroke. Lancet 388:736-738.

111. Yozbatiran N, L Der-Yeghiaian and SC Cramer. (2008). A standardized approach to performing the action research arm test. Neurorehabil Neural Repair 22:78-90.
112. Savitz SI, SC Cramer, L Wechsler and S Consortium. (2014). Stem cells as an emerging paradigm in stroke 3: enhancing the development of clinical trials. Stroke 45: 634-639.

113. Coupar F, A Pollock, P Rowe, C Weir and P Langhorne. (2012). Predictors of upper limb recovery after stroke: a systematic review and meta-analysis. Clin Rehabil 26: 291-313.

114. Diederich NJ and CG Goetz. (2008). The placebo treatments in neurosciences: new insights from clinical and neuroimaging studies. Neurology 71:677-684.

115. Cohen PD, T Isaacs, P Willocks, L Herman, J Stamford, S Riggare and P Wittekind. (2012). Sham neurosurgical procedures: the patients' perspective. Lancet Neurol 11:1022.

116. George AJT, C Collett, AJ Carr, S Holm, C Bale, S Burton, M Campbell, A Coles, G Gottlieb, et al. (2016). When should placebo surgery as a control in clinical trials be carried out?. Royal Coll Surg Bull 98:4.

117. Jin K, X Mao, L Xie, V Galvan, B Lai, Y Wang, O Gorostiza, X Wang and DA Greenberg. (2010). Transplantation of human neural precursor cells in Matrigel scaffolding improves outcome from focal cerebral ischemia after delayed postischemic treatment in rats. $\mathrm{J}$ Cereb Blood Flow Metab 30:534-544.

118. Jin K, X Mao, L Xie, RB Greenberg, B Peng, A Moore, MB Greenberg and DA Greenberg. (2010). Delayed transplantation of human neural precursor cells improves outcome from focal cerebral ischemia in aged rats. Aging Cell 9: 1076-1083.

Address correspondence to:

Dr. John Sinden

ReNeuron

Pencoed Business Park

Pencoed

Bridgend CF35 5 HY

United Kingdom

E-mail: john-sinden@reneuron.com

Received for publication January 11, 2017

Accepted after revision April 14, 2017

Prepublished on Liebert Instant Online April 27, 2017 